\title{
Proper selection of substrates and crops enhances the sustainability of Paris rooftop garden
}

\author{
Erica Dorr $^{1}$ (D) - Esther Sanyé-Mengual ${ }^{2}$ • Benoît Gabrielle ${ }^{3}$ - Baptiste J-P Grard ${ }^{3,4}$. \\ Christine Aubry ${ }^{1}$
}

Accepted: 11 September 2017 / Published online: 11 October 2017

(C) INRA and Springer-Verlag France SAS 2017

\begin{abstract}
Rooftop gardens are a promising way to supplement the growing demand for local food production, and are especially relevant in large cities with acute space constraints. However, they face the challenge of achieving viable food productivity while minimizing their impacts on the environment, two priorities that often oppose one another. Also, the actual impacts of management practices, which are deemed environmentally friendly in principle, are rarely quantified. Therefore, evaluations that encompass all components of urban gardens and a comprehensive range of environmental issues are necessary to reveal potential trade-offs and provide guidance in the design of these systems.

In this study, we evaluated the environmental and economic impacts of rooftop gardening practices, focusing on crop and substrate selection, which are key parameters in system design but whose consequences have seldom been evaluated so far. Life cycle assessment (LCA) and life cycle costing (LCC) were used to analyze a case study in the center of Paris (France). The production systems considered involved crop rotations of tomato and lettuce each grown in three
\end{abstract}

Erica Dorr

ericadorr8@gmail.com

1 INRA, UMR 1048 SADAPT, 75231 Paris, France

2 Research Centre in Urban Environment for Agriculture and Biodiversity (ResCUE-AB), Department of Agricultural Sciences (Dipsa), Alma Mater Studiorum - University of Bologna, Viale Fanin 44, 40126 Bologna, Italy

3 UMR ECOSYS, INRA, AgroParisTech, Université Paris-Saclay, 78850 Thiverval-Grignon, France

4 Laboratoire Ecologie Systématique Evolution, AgroParisTech, CNRS, Université Paris Sud, Université Paris Saclay, 91400 Orsay, France different substrate types: compost and wood chips; compost, wood chips, and earthworms; and conventional potting soil.

Despite the large environmental burdens of compost production, systems with compost performed better environmentally and economically than the system involving potting soil, specifically having $17-47 \%$ less greenhouse gas emissions per kg of product. Across systems, length of cultivation and yield appeared to be the most influential determinants of the environmental impacts. Within the compost systems, the most impactful component was the material used for garden infrastructure, and substrate production for the potting soil systems. This is the first study that considers compost as a substrate, weighs its benefits and impacts, incorporates it into a complete garden, and compares it to potting soil. Our results demonstrate that careful system design could significantly abate environmental impacts. They provide critically needed information to people implementing urban rooftop agriculture and considering the trade-offs involved in each decision.

Keywords Urban agriculture $\cdot$ Rooftop garden $\cdot$ Life cycle assessment $\cdot$ Compost $\cdot$ Substrate $\cdot$ Building-integrated agriculture

\section{Introduction}

\subsection{Role and perceptions of urban agriculture}

Urban populations have large concentrated environmental impacts, and increased urbanization will contribute further to issues such as climate change and pollution. Considering food is one of the top contributors to a city's ecological footprint (Dor and Kissinger 2017), urban agriculture appears as an effective response to mitigate its consequences. It is gaining prominence in developed countries and has moved from the 
fringe to the mainstream (Bohn and Viljoen 2011; Mok et al. 2013), and the purposes and practices span a wide variety of possibilities. Farms designed to maximize different functions may look radically different, from their location to the type of crops grown through the containers they are grown in. A primary apprehension about crops grown in cities was contamination from pollutants in the air and soils, but this concern has been lessened as studies show that urban products are just as safe and nutritious as conventional produce on the ground (Säumel et al. 2012) and on rooftops (Grard et al. 2015). Yields can be comparable to professional land cultivation systems (Grard et al. 2015), but the overall effectiveness in feeding a city varies (McClintock et al. 2013).

\subsection{Opportunities of rooftop agriculture}

Rooftop urban farming has been widely implemented because it circumvents the significant barrier of finding land to cultivate in cities (Badami and Ramankutty 2015). Also called zero-acreage farming (Zfarming) (Specht et al. 2014) and building-integrated agriculture (Caplow 2009), this form of urban gardening can have added benefits of insulating and reducing energy consumption of buildings, extending the lifetime of roofs, and reducing storm water runoff (Ugai 2016), in addition to the potential environmental, social, and economic benefits of all forms of urban gardening (Santo et al. 2016).

\subsection{Current knowledge of urban agriculture design}

Several strategies have been found to make urban gardens low-impact, productive, and well received by the public. Techniques to minimize environmental impacts are to use open-air systems rather than greenhouses, utilize rooftops to avoid land use, grow in soil-based systems, and carefully choose auxiliary materials and crop inputs, as these components carry the largest environmental burden of the overall production system (Sanyé-Mengual et al. 2015a, b; Goldstein et al. 2016). Food production can be maximized when using soilless systems such as aquaponics, growing plants year-round in a greenhouse, and choosing highyielding crops (Sanyé-Mengual et al. 2015a, b). Soil-based systems are the most common form of rooftop agriculture (69\%) (Thomaier et al. 2015), and while $60 \%$ of urban residents in Berlin expressed acceptance of rooftop gardening, $65 \%$ would reject intensive systems such as aquaponics (Specht et al. 2016), further demanding a focus on soilbased systems.

\subsection{Reevaluating urban agriculture sustainability claims}

Careful, educated considerations in urban agriculture design are needed now more than ever as research shows participants falsely assume urban agriculture is inherently sustainable
(Specht et al. 2014). Surprisingly, Goldstein concluded that no form of urban agriculture is more sustainable in all impact categories than conventional agriculture in mild climates, as the benefit of reduced food miles is offset by components unique to each urban agriculture design (Goldstein et al. 2016). Reservations are intensified by findings that solar panels are more efficient at mitigating environmental impacts, such as greenhouse gas emissions, per unit area than rooftop gardens (Goldstein et al. 2016). Also, diet changes have a much more significant effect on the environmental footprint of food consumption than the substitution of conventionally produced food with products of urban agriculture (Kulak et al. 2013).

\subsection{Filling the gaps with life cycle assessment}

Some of the research quantifying benefits and constraints of urban agriculture systems overlook large impacts by only considering the production and distribution stages of a garden, rather than using a lifetime perspective that includes upstream burdens. These studies provide misleading or incomplete information about overall impacts of urban agriculture and how to manage an urban farm in an efficient and low-impact way. In order to justify the sustainability claims of urban agriculture, system design must consider the full life cycle rather than only the production and distribution stages. Although rarely used thus far in the context of urban agriculture (SanyéMengual et al. 2015a, b; Goldstein et al. 2016), life cycle assessment (LCA) is an objective and standardized tool used to quantify environmental burdens, consider complex tradeoffs, and highlight impactful practices in order to guide decision-making (ISO 2006). In this study, LCA was done to compare soil substrates in a low-impact garden in Paris (France), where it is estimated that 80 ha of cultivable rooftop area are available (Agence Parisienne d'Urbanisme 2004) (Fig. 1). Many options are available in terms of substrate selection, and this choice can impact crop yield, environmental, and economic performance in rooftop and ground-based gardens alike. Therefore, this case study uniquely looks at potting soil and compost made from repurposed urban waste. The main goal of this analysis is to assess substrate and crop choice in rooftop agriculture design from an environmental and economic perspective. Here, LCA will identify the most impactful life cycle stage of the garden, highlight specific processes with the largest burden, and allow for comparisons to forms of urban agriculture quantified in other LCAs.

\section{Materials and methods}

This paper uses life cycle assessment and life cycle costing to assess the environmental and economic burdens of food production of an experimental garden in Paris. 
Fig. 1 Portion of the rooftop, open-air, soil-based, low-yield, and low-input garden (left). It is situated in a centrally located neighborhood of Paris, France (top right). A series of T2 treatment replicates with five lettuce plants in each box (bottom right)

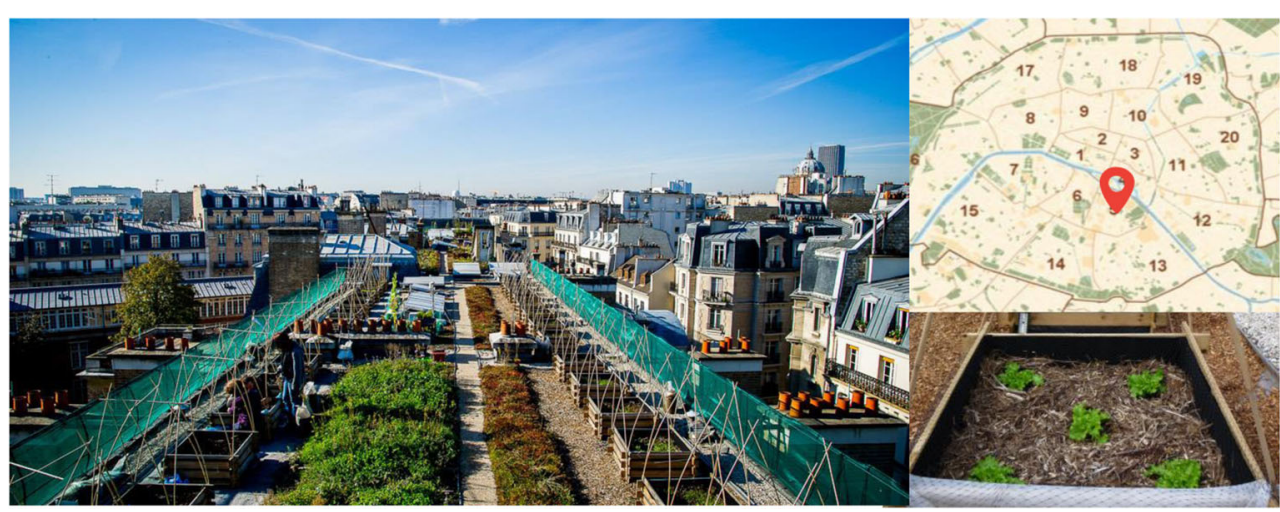

\subsection{Case study description}

The rooftop garden of AgroParisTech was used as the case study, as described by Grard et al. (2015) and shown in Fig. 1. Established in 2012 in the center of Paris, this experimental garden determined the productivity and health safety risks due to atmospheric pollution of food grown in rooftop gardens in dense European cities. Crops were grown in wooden boxes $0.81 \mathrm{~m}^{2}$ in surface area and $0.3 \mathrm{~m}$ in depth, filled with one of three different layered substrates: commercial potting substrate (control system), compost and crushed wood (T1), or compost, crushed wood, and earthworms (T2). The crop rotation consisted of lettuce (Lactuca sativa) from April to May, cherry tomato (Lycopersicum esculentum var. chery) from June to mid-October, and rye and clover from mid-October to March. The soil was tilled between each crop rotation, and residues were left in place only after the winter cultivation of rye and clover. For the purpose of this study, the garden is expected to last 10 years.

\subsection{Life cycle assessment}

The life cycle assessment (LCA) was completed according to ISO 14040 protocol (2006).

\subsubsection{Goal and scope}

The goals of the LCA were to evaluate the effects of different substrate solutions for rooftop gardens in northeast Europe, identify burdensome hotspots of the systems, and compare the three different cultivation designs. The intended users of the results are researchers, urban gardeners, local authorities, and urban developers. The functional unit, a measurement that is normalized across all systems for comparative purposes, was $1 \mathrm{~kg}$ of product (here, tomato or lettuce) grown in a given year. System boundaries extended from the production of raw materials used in the cultivation system to disposal of materials. The distribution and consumption of the garden products were excluded, first because the garden is located in close proximity to the expected consumers and therefore does not require significant transportation or packaging, and second because it was assumed that all crops follow the same path after harvest. The burden of rooftop garden installation and operation on building infrastructure was also excluded due to study constraints. The production systems consist of four life cycle stages: substrate production and acquisition, auxiliary equipment production and acquisition, crop growth, and auxiliary equipment disposal.

Sensitivity analyses were conducted because impacts can vary greatly with realistic changes that may occur in the production system. Three alternatives were considered:

- Industrial scenario: industrial compost is used rather than homemade compost

- Extended scenario: the lifetime of some materials is extended from 10 to 20 years

- Optimized scenario: data is used from the same garden but different boxes and years for a scenario that optimizes yield, substrate volume, and cultivation in winter.

Extrapolating lifetime data Data was collected for 2 years of the expected 10-year lifetime of the garden. The mean of values for the first 2 years could not be used to find average annual values because the first year of cultivation has extreme measurements for many processes that do not represent the system over the long term. For example, water losses, nitrate leaching, and substrate additions were extremely high in the first year, which is an expected and inherent characteristic of agronomic systems. Water quickly filtered through the substrate because a heterogeneous soil structure had not formed yet. Nitrate initially present in the soil solution was rapidly lost by leaching before plants took it up or the soil microbial biomass immobilized it. The substrate was depleted initially because an active, unstable microbial community quickly consumed available organic material, and large additions were needed to replace it. By the second year, these forces stabilized and losses decreased dramatically. To account for this, the system was assumed to have completely stabilized after the second year, so that data obtained during the second year could be extrapolated to the remaining 8 years of the garden's life time. True 
values from the first year were included because although they were high compared to most years, they represent actual processes that would occur in any similar system.

\subsubsection{Life cycle inventory}

Table 1 shows the life cycle inventory (LCI) per functional unit (1 kg of product grown in 1 year) by production system and life cycle stage. Inventory data for foreground processes were directly measured in the experimental garden, such as nitrate leaching and water use. Gaseous agricultural emissions, such as $\mathrm{N}_{2} \mathrm{O}, \mathrm{NH}_{3}$, and $\mathrm{NO}$, were not measured in the garden but were estimated from substrate inputs using a standard emissions factor. The Ecoinvent 3.1 database (Swiss Center for Life Cycle Inventories 2014) and other published life cycle analyses were used for background processes, including production of compost and auxiliary materials.

Substrate production The composition of substrate varied by system:

- Control (C): Sphagnum peat moss and composted bark

- Substrate T1: Compost and crushed wood, layered

- Substrate T2: Compost and crushed wood, layered and inoculated with earthworms
Annual enrichments of substrate 66 were added to maintain nutrient quality and constant volume of $243 \mathrm{~L}$. Regarding T1 and $\mathrm{T} 2$, the initial substrate was half-crushed wood and halfcomposted waste from green spaces in the nearby city of Versailles, but only compost was added annually. The boxes received different amounts of annual compost amendment because the substrate in T2 was depleted faster as earthworms consumed the available organic matter. Earthworms added to each T2 box consisted of 15 Dendrobaena Veneta adults, 35 Eisenia Fetida adults, and 10 Lumbricus Terrestris adults. LCI values for home and industrial composting were used from Martínez-Blanco et al. (2010).

The main environmental benefit provided by compost is avoiding the transportation and decomposition of green waste in landfills, which is critical because when this avoidance is not taken into account, compost production has a higher environmental impact than mineral fertilizer production (Martínez-Blanco et al. 2009). To quantify this avoided burden, the method of system expansion was used (ISO 2006), extending the system boundaries to include the alternative process to composting: incineration. In Paris, green waste from parks is collected for composting, but citizens' kitchen waste is not separated and is either incinerated or buried with all other waste. For the purposes of this model, it was assumed that all green waste would have been incinerated if it had not

Table 1 Life cycle inventory containing input values for the functional unit: $1 \mathrm{~kg}$ of crop grown in 1 year. The life cycle is separated into four stages: substrate production, auxiliary equipment, crop inputs, and disposal

\begin{tabular}{|c|c|c|c|c|c|c|c|c|c|}
\hline \multirow[t]{2}{*}{ Life cycle stage } & \multirow[t]{2}{*}{ Element } & \multirow[t]{2}{*}{ Material } & \multirow[t]{2}{*}{ Unit } & \multicolumn{6}{|c|}{ Production system } \\
\hline & & & & T1 Tomato & T1 Lettuce & T2 Tomato & T2 Lettuce & C Tomato & C Lettuce \\
\hline \multirow[t]{4}{*}{ Substrate production } & \multirow[t]{3}{*}{ Substrate } & Compost & $\mathrm{kg}$ & 14.9 & 14.0 & 10.8 & 17.5 & & \\
\hline & & Wood chips & $\mathrm{kg}$ & 1.4 & 0.48 & 1.4 & 0.48 & & \\
\hline & & Potting soil & $\mathrm{kg}$ & & & & & 22.9 & 8.1 \\
\hline & Transport & $3.5-7.5$ ton lorry & $\mathrm{kg} \mathrm{km}$ & 7.6 & 2.6 & 7.6 & 2.6 & 77.9 & 27.5 \\
\hline \multirow{10}{*}{$\begin{array}{l}\text { Auxiliary equipment } \\
\text { production }\end{array}$} & Netting & Polyethylene & $\mathrm{kg}$ & 0.078 & 0.027 & 0.078 & 0.027 & 0.078 & 0.027 \\
\hline & EPDM & Synthetic rubber & $\mathrm{kg}$ & 0.337 & 0.119 & 0.337 & 0.119 & 0.337 & 0.119 \\
\hline & Support sticks & Bamboo & $\mathrm{kg}$ & 0.052 & 0.018 & 0.052 & 0.018 & 0.052 & 0.018 \\
\hline & Wood & Pine sawnwood & $\mathrm{kg}$ & 0.533 & 0.187 & 0.533 & 0.187 & 0.533 & 0.187 \\
\hline & Screws & Steel & $\mathrm{kg}$ & 0.012 & 0.004 & 0.012 & 0.004 & 0.012 & 0.004 \\
\hline & Geotextile & Polypropylene & $\mathrm{kg}$ & 0.015 & 0.005 & 0.015 & 0.005 & 0.015 & 0.005 \\
\hline & Clay balls & Expanded clay & $\mathrm{kg}$ & 1.14 & 0.40 & 1.14 & 0.40 & 1.14 & 0.40 \\
\hline & Irrigation pipe & Polypropylene & $\mathrm{kg}$ & $1.8 \mathrm{E}-3$ & $0.6 \mathrm{E}-3$ & $1.8 \mathrm{E}-3$ & $0.6 \mathrm{E}-3$ & $1.8 \mathrm{E}-3$ & $0.6 \mathrm{E}-3$ \\
\hline & Drip tape & Polyethylene & $\mathrm{kg}$ & $0.7 \mathrm{E}-3$ & $0.3 \mathrm{E}-3$ & $0.7 \mathrm{E}-3$ & $0.3 \mathrm{E}-3$ & $0.7 \mathrm{E}-3$ & $0.3 \mathrm{E}-3$ \\
\hline & Transport & $3.5-7.5$ ton lorry & $\mathrm{kg} \mathrm{km}$ & 7.37 & 2.59 & 7.37 & 2.59 & 7.37 & 2.59 \\
\hline \multirow[t]{3}{*}{ Crop Growth } & Irrigation & Tap water & L/day & 0.88 & & 0.88 & & 0.88 & \\
\hline & Organisms & Earthworm & $\mathrm{kg}$ & & & 0.016 & 0.016 & & \\
\hline & Transport & Small car & $\mathrm{kg} \mathrm{km}$ & & & 0.054 & 0.054 & & \\
\hline \multirow{3}{*}{$\begin{array}{l}\text { Auxiliary equipment } \\
\text { disposal }\end{array}$} & Waste recycled & Mixed waste & $\mathrm{kg}$ & 0.10 & 0.03 & 0.10 & 0.03 & 0.10 & 0.03 \\
\hline & Waste incinerated & Mixed waste & $\mathrm{kg}$ & 2.1 & 0.70 & 2.1 & 0.70 & 2.1 & 0.70 \\
\hline & Transport & 21 ton lorry & $\mathrm{kg} \mathrm{km}$ & 9.11 & 3.20 & 9.11 & 3.20 & 9.11 & 3.20 \\
\hline
\end{tabular}


been diverted to composting. The amount of green waste needed to produce the compost used was determined based on the mass balance of the composting process (MartínezBlanco et al. 2009; Colón et al. 2010), and the environmental burden of sending this amount of green waste to a landfill to be incinerated is calculated and subtracted from the impact of compost.

Physical allocation was used to distribute the impact of compost based on how much nitrogen the crops took up, which had been previously calculated. The winter cover crops, clover, and rye, were mixed into the soil in March as green manure. Because they are not products, inputs associated with clover and rye cultivation were allocated temporally to lettuce and tomato.

Carbon stored in the soil and plants of the garden was calculated using the Rothamstead Carbon Model (Coleman and Jenkinson 2014). Data used in the model include weather data from the Parc Montsouris meteorological station in Paris (located about $3 \mathrm{~km}$ away from the garden), open pan evaporation, clay content, which was assumed to be 0 considering the substrates used, monthly inputs of plant residue material, which was calculated from the carbon content of crops grown (Magnussen and Reed 2014), and the ratio of decomposable to resistant organic matter in the substrates (Houot et al. 2014). The RothC model was run over the 10-year lifetime of each production system and provided monthly outputs of soil organic $\mathrm{C}$ changes. Changes were attributed to each crop based on the months over which each crop was cultivated and compounded over the garden's lifetime.

Auxiliary equipment production Extensive initial inputs are required to transform an abiotic building rooftop into a space suitable for crop cultivation. A layer of EPDM (ethylene propylene diene monomer), a synthetic rubber, was placed under each box to prevent root and water damage to the building, and a rigid net $2.5 \mathrm{~m}$ tall was installed surrounding the garden to prevent birds from consuming crops. Wooden panels, screws, expanded clay balls for water catchment, geotextile lining the inside of boxes, irrigation pipes, and drip tape composed the cultivation boxes. Although reused materials can be used to build gardens, it is not common in Paris, so new materials were used for the case study. Impacts were distributed temporally. Most materials were acquired from local hardware stores 3-5 km away from the garden, with the exception of EPDM, which could only be found $28 \mathrm{~km}$ away because it is a specialty product.

Crop inputs Tomatoes were irrigated with tap water from sprinklers and a drip system. Irrigation rates were adjusted manually and varied throughout the season, but an approximate average of $1.1 \mathrm{~L} \mathrm{~m}^{2}$ per day was used for the study. Lettuce and green manure were not irrigated and were only watered with rainwater.
Auxiliary equipment disposal Plastic irrigation pipes, netting, drip tape, and geotextile membranes will be recycled at the end of the life of the garden. Substrates will be donated and reused at other gardens in Paris. The non-recyclable materials (brick, EPDM rubber, wood panels, screws, and wooden support sticks for the netting) are sent to a landfill $4.2 \mathrm{~km}$ away from the garden. The "cut off" method is employed to allocate the burdens of disposing recyclable materials to the system that they will be adopted by (Ekvall and Tillman 1997).

\subsection{Life cycle impact assessment}

The life cycle impact assessment was completed according to the ISO 14040 protocol (ISO 2006), including the classification and characterization stages using a hierarchical perspective. The environmental impact categories considered are midpoint categories as described by ReCiPe 2008 (Goedkoop et al. 2009), and include climate change, human toxicity, water depletion, marine eutrophication, and fossil depletion. These indicators were chosen because they reflect issues that are prominent in agricultural systems. Calculations were performed using SimaPro 8.2 software (Pré Consultants, 2016). Statistical tests were done through Monte Carlo analyses in the SimaPro software and RStudio.

\subsection{Life cycle costing}

A life cycle cost analysis (ISO 2008) evaluated the economic impacts of the garden, using total cost as an indicator. The cost of materials was obtained from local stores in Paris, and the cost of waste treatment and water use was considered. The cost of gas for transportation was not considered because all products are locally acquired and disposed of close to the garden.

\section{Results and discussion}

Table 2 shows the results for product systems for the environmental and economic indicators.

\subsection{Substrate comparison}

Systems using compost as a substrate had lower impacts than those using potting soil for all categories. Although compost production was the largest contributor to climate change in $\mathrm{T} 1$ and T2 (67-89\%, including environmental credit) and significant in marine eutrophication (5-27\%, including environmental credit), these systems overall had lower impacts than the control because their higher yields effectively diluted the environmental burdens assigned to each unit of product. Additionally, the production of potting soil in the control came with its own burdens (Fig. 3).

T2 had lower impacts than T1, except for lettuce in the climate change and human toxicity categories, where they 
Table 2 The characterization of impacts show the importance of each system to the indicators. Control systems have consistently highest impacts, whereas T2 systems have the lowest. Tomato systems are generally more impactful than lettuce systems of the same treatment

\begin{tabular}{|c|c|c|c|c|c|c|c|}
\hline \multirow[t]{2}{*}{ Impact category } & \multirow[t]{2}{*}{ Units } & \multicolumn{6}{|c|}{ Product system } \\
\hline & & T1 Tomato & $\mathrm{T} 2$ Tomato & C Tomato & T1 Lettuce & T2 Lettuce & C Lettuce \\
\hline Climate change & $\mathrm{kgCO}_{2}$ eq & 4.24 & 2.74 & 5.17 & 2.85 & 1.71 & 4.69 \\
\hline Water depletion & $\mathrm{m}^{3}$ & 0.0517 & 0.0486 & 0.116 & -0.0124 & -0.00812 & 0.00111 \\
\hline Human toxicity & kg 1.4-DB eq & 0.013 & -0.0518 & 0.988 & -0.225 & -0.309 & 0.888 \\
\hline Fossil depletion & $\mathrm{kg}$ oil eq & 0.164 & 0.132 & 1.09 & 0.0217 & -0.0119 & 0.988 \\
\hline Marine eutrophication & $\mathrm{kg} \mathrm{N}$ eq & 0.00611 & 0.00477 & 0.0173 & 0.00217 & 0.00103 & 0.0156 \\
\hline Cost & $€$ & 4.29 & 3.71 & 5.59 & 1.3 & 0.694 & 4.85 \\
\hline
\end{tabular}

were not statistically different according to SimaPro Monte Carlo analysis. The only difference in these systems is addition of earthworms to T2, which comes with negligible burdens and many agronomic benefits. In this analysis, they contribute to increased rate of substrate loss, leading to more compost additions to the system, and increased yields, which resulted in lower impacts.

Because compost production contributes significantly to global warming potential, among other categories, it should be noted that strict regulation of composting practices could reduce these burdens. Within a home composting practice, factors such as frequency of mixing, humidity, temperature, and composition of green waste inputs directly determine gaseous emissions during the decomposition phase (Boldrin et al. 2009; Quirós et al. 2014). Indirect and downstream emissions are affected by the composition and source of a composting bin, and the material that compost is intended to replace in application, such as peat (Boldrin et al. 2009).

\subsection{Comparison of life cycle stages}

An analysis was done of the 8-16 processes whose contributions made up at least $95 \%$ of each impact (Fig. 2). The results for each category are mixed, but the substrate and auxiliary material production stages appear to be consistent major contributors. Substrate production is more impactful in control systems than in compost, except for the climate change category, and auxiliary materials are usually more important in compost systems. This difference is largely because compost production receives environmental credits, reducing the $\mathrm{T} 1$ and T2 substrate impacts and effectively giving auxiliary material production a larger proportion.

The biggest contributor to climate change in $\mathrm{T} 1$ and $\mathrm{T} 2$ was compost production, and for the control was diesel used in plant waste collection for composted bark production (20$28 \%$ ) and peat production (22\%). Significant processes for marine eutrophication were wood production for the boxes in $\mathrm{T} 1(35 \%), \mathrm{T} 2(46 \%)$, and $\mathrm{C}(30 \%)$, wastewater treatment in all systems (7-10\%), composted bark in C (20\%), and compost production in T1 $(30-45 \%)$ and T2 (16\%). The disposal stage was particularly impactful to human toxicity because incineration alone contributed $30 \%$ from C, $40-45 \%$ from $\mathrm{T} 1$, and $45-58 \%$ from $\mathrm{T} 2$. The largest contributor to fossil depletion from the control was diesel for composted bark production (25\%), while from $\mathrm{T} 1$ and $\mathrm{T} 2$, the biggest contributors were EPDM (10-20\%) and netting production
Fig. 2 Percent contributions from life cycle stages (substrate production, auxiliary material production, crop inputs, and auxiliary material disposal) to each impact category. Values from $\mathrm{T} 1$ and $\mathrm{T} 2$ were combined because they show the same pattern, and water depletion was separated by crop because tomatoes had a large impact from irrigation in the crop inputs stage, while lettuce was not irrigated
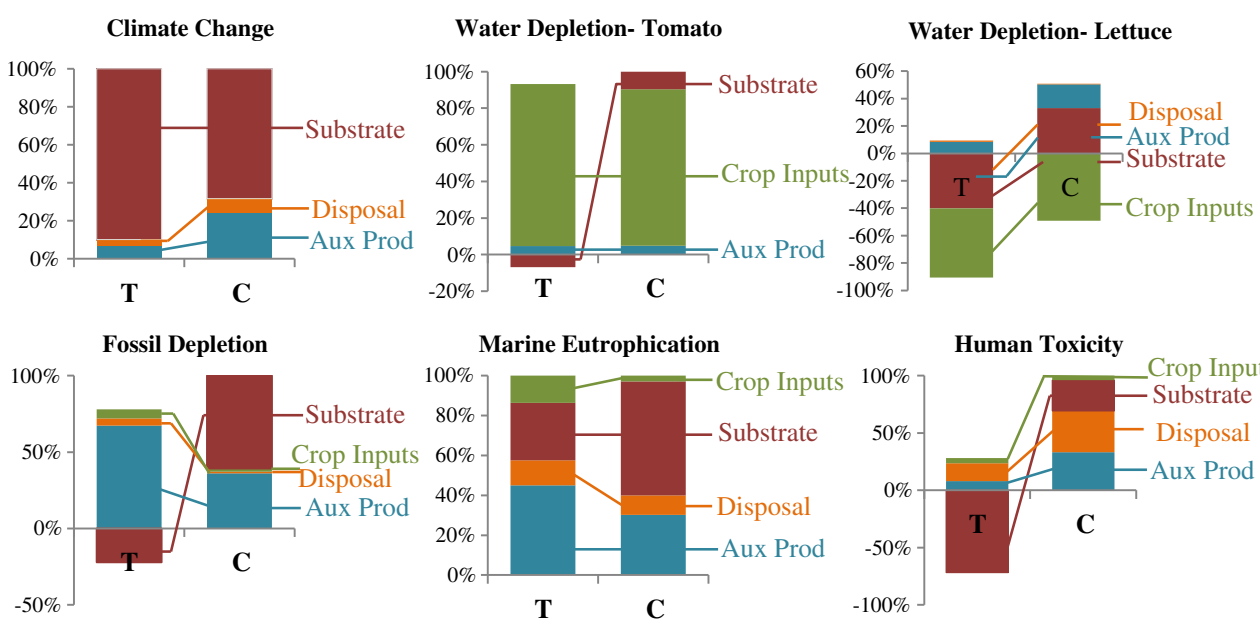

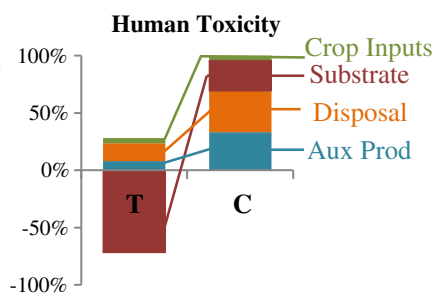


(41-68\%), but the recycling of netting nearly offset its input. Impacts of clay ball production were ubiquitous, contributing $5-10 \%$ to all impacts in all systems, although it is never a major contributor. Among auxiliary materials, the objects with major total impacts are clay balls, wood, and EPDM. It should be noted that most roofs are covered with a protective membrane anyway, so the layer implemented here was redundant and could easily be avoided. Additionally, crops could be grown in larger containers or directly on the roof in order to eliminate the use of wood panels and screws for boxes.

Irrigation of tomatoes was the major process involved in water depletion, contributing to $85-88 \%$ of the impact, only followed by a long list of processes all contributing $4 \%$ and less. For lettuce, the wastewater treatment process results in negative water depletion, because the output is clean water, and this contributed $55-80 \%$ of negative impact in the crop inputs category. Ultimately, water depletion was negligible when the impact indicators were normalized and compared.

\subsection{Trend in yield and cultivation length}

The impact of a crop production system is most strongly determined by its biomass yield and length of cultivation. Because many burdens come from auxiliary materials, more efficient boxes with higher yields were allocated fewer impacts per functional unit. To explore this, an "impact factor" is calculated by dividing the number of days in a year a crop was grown for by its yield. This impact factor strongly correlates to the impacts for all environmental $(0.77<r<0.91)$ and economic $(r=0.99)$ indicators. Tomatoes had consistently higher impacts than lettuce, first because their longer growing season resulted in a larger proportion of the impact from auxiliary materials allocated to them (73.8\%), and second because they had low yields $\left(2.18 \mathrm{~kg} \mathrm{~m}^{-2}\right.$ fresh product for $\mathrm{T} 1$ and $2.53 \mathrm{~kg} \mathrm{~m}^{-2}$ for T2) compared to lettuce (2.6 and $4.9 \mathrm{~kg} \mathrm{~m}^{-2}$ ). This exceptionally low yield may be due to several factors, including the choice of a cherry variety, which by its nature produces less biomass per unit area than regular tomatoes. Also, a fungal disease affected the tomatoes throughout the growing season during the second year. The control system had the greatest impacts because of its low yield $\left(0.62 \mathrm{~kg} \mathrm{~m}^{-2}\right.$ for lettuce, $1.61 \mathrm{~kg} \mathrm{~m}^{-2}$ for tomato), while system $\mathrm{T} 2 \mathrm{had}$ the least impact because it consistently had the highest yields. Rye and clover yields did not follow this trend, yielding $0.67,0.45$, and $0.30 \mathrm{~kg} \mathrm{~m}^{-2}$ for $\mathrm{T} 1, \mathrm{~T} 2$, and $\mathrm{C}$, respectively, but they are not directly assessed in the LCA because they do not make a food product.

\subsection{Carbon sequestration}

All tomato systems sequestered more carbon than lettuce systems due to the longer growing cycle and greater allocation to tomato, along with more input plant residue. When considering substrate type, systems $\mathrm{T} 1$ and $\mathrm{T} 2$ sequestered 101 and $49 \mathrm{~g} \mathrm{C} / \mathrm{m}^{2}$ over 10 years, respectively, while the control emitted $37 \mathrm{~g} \mathrm{C} / \mathrm{m}^{2}$ over 10 years. Ultimately, these changes in soil carbon content are negligible compared to the overall impact on climate change from the garden's lifetime, accounting for only $0.2-3 \%$ of the carbon dioxide equivalents emitted.

There are limitations with the RothC model here because it is designed for agricultural systems having much less organic matter, and it does not consider carbon mineralization or other greenhouse gasses relevant to agricultural systems, such as nitrous oxide. This inaccuracy could be mitigated by directly measuring carbon mineralization and including it in a different model, along with designing a model specific to urban or small-scale gardens.

\subsection{Life cycle cost}

The life cycle cost of each production system followed the general trend seen for all impacts, correlating strongly to the yield and the duration of cultivation $(r=0.99)$. As a result, systems with tomatoes and the control substrate were most expensive. The largest cost item was netting, which accounted for $65-73 \%$ of the total cost. Tomatoes were produced at a reasonable cost in $\mathrm{T} 2$, comparable to the average regional market price of cherry tomatoes of $€ 3.75 / \mathrm{kg}$ (FranceAgriMer 2017), and lettuce was produced at a reasonable cost in boxes $\mathrm{T} 1$ and T2, compared to the average regional market price of $€ 2.14 / \mathrm{kg}$ (FranceAgriMer, 2017). An urban production price that is competitive with retail price is important to ensure urban agriculture is a realistic alternative or at least a supplement to conventional food production.

\subsection{Alternative scenarios}

It was found that replacing home composting with industrial composting had mixed effects. A key difference is that the industrial method uses more green waste to make an equivalent amount of home compost $(6.88 \mathrm{~kg}$ waste yields $1 \mathrm{~kg}$ industrial compost, compared to $1.78 \mathrm{~kg}$ input waste for home compost). Therefore, since industrial composting removes more green waste from the flow into landfills, it receives large credits and a reduction in climate change potential by $100 \%$. Human toxicity is reduced by a factor of 4 due to the larger environmental credit from avoiding the landfilling of green waste. Furthermore, industrial composting releases less toxins and greenhouse gasses directly into the atmosphere because facilities are equipped with air filters (Martínez-Blanco et al. 2010). The tradeoff is extensive use of municipal waste trucks to collect green waste, which increases fossil depletion by a factor of 2.5 for tomatoes and 11.3 for lettuce. A comparison of this scenario to the real garden, and other alternative scenarios, is found in Fig. 3. 


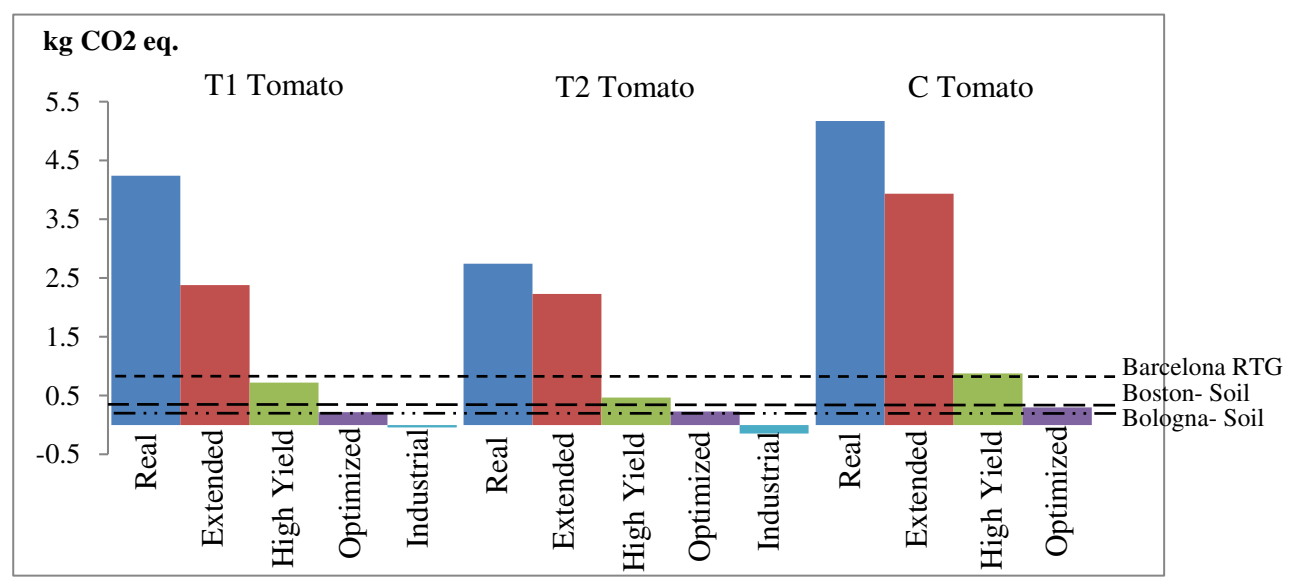

Fig. 3 Climate change impacts from alternative scenarios of each tomato system are compared side by side to show the lessened impact of each scenario. "Extended" results are obtained by changing the lifetime of auxiliary materials from 10 to 20 years. The "High Yield" scenario uses the high yield from the optimized scenario, but excludes the substrate and

year-round productivity factors, and the "Optimized" scenario includes all three of these adjustments. "Industrial" uses industrial compost production rather than at-home production. Reference lines to tomato climate change impact from other gardens overlap the graph

A scenario where the lifetime of impactful auxiliary materials (netting, EPDM, and clay balls) is extended from 10 to 20 years results in $62-66 \%$ savings in costs, resulting in competitive prices for all systems except control lettuce. Reductions in environmental impacts are seen for all issues, particularly in the fossil depletion category, which has an average reduction of $45 \%$. Control systems also have $40 \%$ reductions in climate change and $30 \%$ in human toxicity. T1 and $\mathrm{T} 2$ tomato systems saw reductions in human toxicity of a factor of 2 and 7, respectively, and $12 \%$ reductions in climate change. The actual maximum lifetime of these materials varies based on their durability, maintenance, and lifetime of the garden as a whole.

This case study uses the first years of an experimental garden, which revealed several limitations. A study in the same garden in 2015 offers an optimized scenario, where tomato with T1 substrate was grown with five plants per box in a rotation with a productive winter crop (spinach, garlic, other lettuce varieties, or cabbage) rather than a green manure. The increased plant density, full-size tomato variety, and climate variability resulted in a maximum yield of $11.0 \mathrm{~kg} / \mathrm{m}^{2}$, which reduced all impacts by $83 \%$. The lack of allocated burdens from an unproductive green manure further reduced impacts by $2-6 \%$, except for water depletion $(0.05 \%$ reduction) and human toxicity ( $76 \%$ reduction). Additionally, data was measured for more years, and it was found that substrate depletion continued to decrease after the second year. This lower substrate use further reduces climate change impact by $11 \%$ and marine eutrophication by $3 \%$, but increases water depletion, fossil depletion, and human toxicity. These increases are due to the lost credits from compost use. Ultimately, this optimized scenario has impacts reduced by 82 $95 \%$, except for human toxicity, which triples. The cost in this optimized scenario was $€ 0.64 / \mathrm{kg}$, which is below market value for comparable full size variety (FranceAgriMer, 2017).

\subsection{Comparisons to other gardens}

Compared to a similar rooftop, open-air, soil-based urban garden in Boston (Massachusetts) (Goldstein et al. 2016), both $\mathrm{T} 1$ and T2 systems had significantly higher climate change impacts but lower water depletion. Major differences are that the experimental nature of the Paris garden limited the size of boxes and density of plants, and the Boston garden had much higher yields, had the burden of building infrastructure, was not assigned compost production impacts, and was given credits from avoided building energy consumption.

In a comparison to a similar soil-based system in Bologna (Italy) (Sanyé-Mengual et al. 2015b), the Paris garden had dramatically higher climate change impacts, lower water depletion, and mixed human toxicity. Main differences between the case studies are that the Bologna garden had higher yields, used much less compost, used recycled wood and pipes, and irrigated all crops year-round. Additionally, climatic differences cause variation between all compared gardens. In the same garden, lettuce in a hydroponics system had higher climate change impacts than those in Paris, while lettuce floating in water in a recycled wooden container had lower impacts.

Compared to a private rooftop garden in Barcelona using perlite as a substrate (Sanyé-Mengual 2015), lettuce with similar yields had climate change impacts lower than $\mathrm{T} 1$ and $\mathrm{T} 2$ in Paris. Tomatoes had dramatically lower impacts in Barcelona, but also had much higher yields.

A comparison of the optimized scenario with the literature is more interesting, because the massive disparity between yield was erased and other factors of the garden can be considered. Here, only climate change values were compared because it is the impact most consistently assessed. The Paris garden had a $63 \%$ lower impact than the conventional food 
supply of tomatoes grown in rural areas (Swiss Center for Life Cycle Inventories 2014), but three times higher than the equivalent Bologna tomato production (Sanyé-Mengual et al. 2015b), suggesting that the burden from intensive compost use is not offset even with greatly increased yields, and highlighting the importance of using recycled materials. The Paris garden has a $16 \%$ lower impact than the Boston garden.

The case study garden has the advantage of extreme proximity to the consumer and avoids the burden of product transportation. Including product distribution in this study would allow for a more balanced comparison between this rooftop garden and a similar system located farther from the consumer, evidencing a possible benefit of urban agriculture over conventional methods.

\subsection{Considerations for LCI modeling}

The limitations in comparing these systems highlighted components of LCIs that have dramatic impacts on rooftop agriculture LCA outcomes. Crop yield was a strong driver, which is highly dependent on climate conditions, as appeared when comparing Mediterranean cities to Paris. System design, such as plant density and area of cultivation boxes, also affects crop yield. Therefore, the inclusion of scenarios with variable crop yields is essential. System boundaries can be set to exclude essential processes, such as substrate production, or to allocate materials to the system of interest or to another system. For example, EPDM could be allocated to the garden or to the initial roof construction, or materials can be considered recyclable to allocate their impacts to downstream systems. Similarly, system expansion could be used to include indirect benefits, such as building insulation, carbon sequestration, or reduced storm water runoff, but these should be included with caution because they are difficult to measure and are often omitted, resulting in inconsistencies in modeling and uncomparable studies. Lastly, alternative characterization methods may be used, such as the Water Footprint method. The latter includes green water and here would give lettuce a larger water depletion impact despite its lack of irrigation. LCA practitioners should pay special attention to these factors when modeling rooftop gardens.

Accuracy and repeatability are essential but difficult components of LCA, where results of studies are often used in inventories elsewhere. Measured values were used for foreground processes and are accurate here, but are only valid for this case study. They may be applicable to similar systems, but variations between the two should be accounted for. For example, gardens exposed to harsh winter weather or designed for purposes other than food production, such as this one, may implement a winter cover crop that does not produce an edible product. However, urban agriculture systems that do cultivate a productive winter crop can avoid allocating the winter crop burdens to successive crops. Also, values taken from other LCAs, such as those for composting emissions, can be highly variable and are not completely representative of our system as they were adopted from other case studies. Regardless, LCAs of representative scenarios were chosen to minimize variations. Finally, using background processes from SimaPro and Ecoinvent assumes some deviation of accuracy because the systems measured there were not repeated exactly here. The Ecoinvent database is a commonly used and reliable resource for LCA, but may lead to inaccuracies when a specific process is not available and has to be approximated with a similar process. In order to mitigate these inaccuracies, we chose background processes that were closest to the local situation.

\subsection{Summary of findings}

First, regarding substrate choice, Sanyé-Mengual determined that soil-based urban agriculture had lower impacts than hydroponic systems (2015b), highlighting the need for research into an optimal soil-based substrate. Compost appeared as a good candidate because its benefits on crop yield and soil quality were established (Eldridge et al. 2014), and it outperformed mineral fertilizer when applied as an amendment, despite the environmental burden of the compost production phase (Martínez-Blanco et al. 2009). Here, we considered compost as a substrate and compared it to potting soil, and similarly found that it is the environmentally and economically favorable choice overall. Therefore, urban agriculture practitioners should incorporate compost when preparing a substrate and apply earthworms or similar soil macro-organisms. However, considering the burden of compost production, a mix of compost and a lowerimpact material should be used as long as the yieldincreasing benefits of compost remain. Further studies are needed to determine this optimal mix.

Second, although it was known that auxiliary materials contributed the most impact in greenhouse and multi-tunnel systems (Sanyé-Mengual et al. 2015a), here we showed that they were similarly important in open-air systems. In application, these results reinforced Sanyé-Mengual's suggestion (2015b) that practitioners focus on recycling and re-use when acquiring and disposing of materials. Practitioners should minimize the use of materials that cannot feasibly be acquired in these ways.

Third, research showed that high yielding crops had low environmental impacts when compared to low yielding crops (Sanyé-Mengual et al. 2015a, b). We affirmed this principle and further implicated length of cultivation as a factor correlating to environmental and economic impact. Not only should crops with high yields be chosen, but crops with shorter cultivation times should also be considered. 


\section{Conclusion}

This analysis quantified the environmental and economic performance of lettuce and tomato grown in several substrates, using a life cycle perspective to include complex and potentially contradicting factors. Previous studies addressed environmental impacts and benefits of compost as a soil amendment (Martínez-Blanco et al. 2009; Eldridge et al. 2014), while we considered compost as the primary substrate, providing a comparison to potting soil. Additionally, previous life cycle assessments have looked at many urban agriculture designs, identifying low-impact techniques such as open-air, soil-based, high-yielding crop systems (Sanyé-Mengual et al. 2015a, b). We adopted these low-impact techniques and assessed the overall impacts on the environment and economic costs. The compost production stage contributed the most toward climate change, but also contributed to increased yields, revealing a trade-off between productivity and climate change mitigation. In the end, the yield benefits dominated since systems that used compost had overall lower impacts in all categories. Although compost-based systems performed best in this garden, comparisons to other gardens where compost is a supplement rather than the main substrate show similarly high yields and further reduced environmental impacts, suggesting diminishing returns in compost use. The addition of earthworms may seem minor, but their impacts on yield and substrate depletion resulted in large environmental benefits. Overall, the impact of a production system was strongly correlated to its yield and cultivation time, resulting in greater burdens for the low-yielding tomato systems. The stage with the largest environmental impact for compost systems is the production of auxiliary materials, among which clay balls, wood, and EPDM appeared particularly important. For the control systems, the production of potting soil contributed the largest share of environmental impacts. However, disposal of materials and crop inputs are still substantially impactful and should not be ignored. Lastly, although some atmospheric $\mathrm{CO}_{2}$ was sequestered in compost systems, the amount was negligible compared to the amount of greenhouse gasses emitted during the system's lifetime.

Using this information, gardens can be designed to minimize the use of, or replace, the most impactful materials. Compost should be used, but further studies should determine the optimal amount to minimize climate change potential. Auxiliary materials should be recycled from other sites and should be used as long as possible, and their final fate should be reused in another garden to avoid disposal burdens. As other studies suggest, high-yield crops should be chosen. These results add to a growing body of work that informs stakeholders with quantified data and leads to more sustainable urban garden designs.

\section{References}

Agence Parisienne d'Urbanisme (2004) Le verdissement des toits à Paris. http://www.apur.org/etude/verdissement-toits-paris. Accessed 25 June 2017

Badami MG, Ramankutty N (2015) Urban agriculture and food security: a critique based on an assessment of urban land constraints. Glob Food Secur 4:8-15. https://doi.org/10.1016/j.gfs.2014.10.003

Bohn K, Viljoen A (2011) The edible city: envisioning the continuous productive urban landscape (CPUL). Field J 4:149-161

Boldrin A, Andersen JK, Møller J et al (2009) Composting and compost utilization: accounting of greenhouse gases and global warming contributions. Waste Manag Res 27:800812. https://doi.org/10.1177/0734242X09345275

Caplow T (2009) Building integrated agriculture: philosophy and practice. In: urban futures 2030: urban development and urban lifestyles of the future. Heinrich-Böll-Stiftung, Thailand, pp 48-51

Coleman K, Jenkinson DS (2014) RothC-A model for the turnover of carbon in soil. Rothamstead Research, Harpenden

Colón J, Martínez-Blanco J, Gabarrell X et al (2010) Environmental assessment of home composting. Resour Conserv Recycl 54:893904. https://doi.org/10.1016/j.resconrec.2010.01.008

Dor A, Kissinger M (2017) A multi-year, multi-scale analysis of urban sustainability. Environ Impact Assess Rev 62:115-121. https://doi.org/10.1016/j.eiar.2016.05.004

Ekvall T, Tillman A-M (1997) Open-loop recycling: criteria for allocation procedures. Int J Life Cycle Assess 2:155-162. https://doi.org/10. 1007/BF02978810

Eldridge S, Yin Chan K, Donovan N (2014) Agronomic, soil quality and environmental consequences of using compost in vegetable production. In: Composting for sustainable agriculture. Springer, Cham, pp 125-149

Goedkoop M, Heijungs R, HuijbregtsMet al (2009) ReCiPe 2008, a life cycle impact assessment method which comprises harmonised category indicators at the midpoint and the endpoint level; first edition report I: characterisation. Ministerie van VROM, Den Haag

Goldstein B, Hauschild M, Fernández J, Birkved M (2016) Testing the environmental performance of urban agriculture as a food supply in northern climates. J Clean Prod 135:984-994. https://doi.org/10. 1016/j.jclepro.2016.07.004

Grard BJ-P et al (2015) Recycling urban waste as possible use for rooftop vegetable garden. Future Food J Food Agric Soc 3:21-34

Houot S, Pons M-N, Pradel M et al (2014) Valorisation des matières fertilisantes d'origine résiduaire sur les sols à usage agricole ou forestier, impacts agronomiques, environnementaux, socioéconomiques (MAFOR). Expertise scientifique collective. INRA, Paris

ISO (2006) ISO 14040: Environmental management - life cycle assessment - principles and framework

ISO (2008) ISO 15686-5: Buildings and constructed assets - service-life planning - part 5: life-cycle costing

Kulak M, Graves A, Chatterton J (2013) Reducing greenhouse gas emissions with urban agriculture: a life cycle assessment perspective. Landsc Urban Plan 111:68-78. https://doi.org/10.1016/j. landurbplan.2012.11.007

Magnussen S, Reed D (2014) Knowledge reference for national forest assessments-modeling for estimation and monitoring. http://www. fao.org/forestry/17111/en/. Accessed 13 Jul 2016

Martínez-Blanco J, Colón J, Gabarrell X et al (2010) The use of life cycle assessment for the comparison of biowaste composting at home and full scale. Waste Manag 30:983-994. https://doi.org/10.1016/j. wasman.2010.02.023

Martínez-Blanco J, Muñoz P, Antón A, Rieradevall J (2009) Life cycle assessment of the use of compost from municipal organic waste for 
fertilization of tomato crops. Resour Conserv Recycl 53:340-351. https://doi.org/10.1016/j.resconrec.2009.02.003

McClintock N, Cooper J, Khandeshi S (2013) Assessing the potential contribution of vacant land to urban vegetable production and consumption in Oakland, California. Landsc Urban Plan 111:46-58. https://doi.org/10.1016/j.landurbplan.2012.12.009

Mok H-F, Williamson V, Grove J et al (2013) Strawberry fields forever? Urban agriculture in developed countries: a review. Agron Sustain Dev 24:21-43. https://doi.org/10.1007/s13593-013-0156-7

Quirós R, Villalba G, Muñoz P et al (2014) Environmental assessment of two home composts with high and low gaseous emissions of the composting process. Resour Conserv Recycl 90:9-20. https://doi. org/10.1016/j.resconrec.2014.05.008

Santo R, Palmer A, Kim B (2016) Vacant Lots to Vibrant Plots. Johns Hopkins Center For A Livable Future. https://.jhsph.edu/research/ centers-and-institutes/johns-hopkins-center-for-a livablefuture/_pdf/ research/clf_reports/urban-ag-literature-review.pdf. Accessed 27 June 2016

Sanyé-Mengual E (2015) Sustainability assessment of urban rooftop farming using an interdisciplinary approach. Dissertation, Universitat Autònoma de Barcelona. doi: 10.13140/RG.2.1.1346.6089

Sanyé-Mengual E, Oliver-Solà J, Montero JI, Rieradevall J (2015a) An environmental and economic life cycle assessment of rooftop greenhouse (RTG) implementation in Barcelona, Spain. Assessing new forms of urban agriculture from the greenhouse structure to the final product level. Int J Life Cycle Assess 20:350-366. https://doi.org/ 10.1007/s11367-014-0836-9

Sanyé-Mengual E, Orsini F, Oliver-Solà J et al (2015b) Techniques and crops for efficient rooftop gardens in Bologna, Italy. Agron Sustain Dev. https://doi.org/10.1007/s13593-015-0331-0

Säumel I, Kotsyuk I, Hölscher M et al (2012) How healthy is urban horticulture in high traffic areas? Trace metal concentrations in vegetable crops from plantings within inner city neighbourhoods in Berlin, Germany. Environ Pollut 165:124-132. https://doi.org/10. 1016/j.envpol.2012.02.019

Specht K, Siebert R, Hartmann I et al (2014) Urban agriculture of the future: an overview of sustainability aspects of food production in and on buildings. Agric Hum Values 31:33-51. https://doi.org/10. 1007/s10460-013-9448-4

Specht K, Weith T, Swoboda K, Siebert R (2016) Socially acceptable urban agriculture businesses. Agron Sustain Dev. https://doi.org/ 10.1007/s13593-016-0355-0

Swiss Center for Life Cycle Inventories (2014) Ecoinvent data v3.1

Thomaier S, Specht K, Henckel D et al (2015) Farming in and on urban buildings: present practice and specific novelties of zero-acreage farming (ZFarming). Renew Agric Food Syst 30:43-54. https:// doi.org/10.1017/S1742170514000143

Ugai T (2016) Evaluation of sustainable roof from various aspects and benefits of agriculture roofing in Urban Core. Procedia - Soc Behav Sci 216:850-860. https://doi.org/10.1016/j.sbspro.2015.12.082 